\title{
Children and carer's experience and satisfaction of two local anaesthetic techniques; for treatment of carious mandibular primary molars in children
}

\author{
Tahmassebi JF, BaniHani A,Alzahrani F \\ Department of Paediatric Dentistry, University of Leeds, UK
}

Correspondence: Tahmassebi JF, Department of Paediatric Dentistry, Leeds School of Dentistry, University of Leeds, UK, Tel 0II334333955, Email j.tahmassebi@leeds.ac.uk

Received: March 0I, 20I8 | Published: May 16, 2018

Copyright@ 2018 Tahmassebi et al. This is an open access article distributed under the terms of the Creative Commons Attribution License, which permits unrestricted use, distribution, and reproduction in any medium, provided the original author and source are credited.

\begin{abstract}
Background: Local anaesthesia (LA) forms the backbone of pain control techniques in dentistry and has a major role in dentistry for children. Inferior Dental Nerve Block (IDNB) has been the LA technique of choice for treatment of carious mandibular primary molars in children. However, several disadvantages have been associated with the IDNB. Buccal Infiltration (BI) with 4\% Articaine have been proposed as more comfortable and pleasant alternative LA techniques to IDNB which became widely used in paediatric dentistry especially for the treatment of carious mandibular primary molars in children above the age of 4 years.

Aim: To explore children and carer's experience and satisfaction of their child's dental treatment under LA and compare their acceptance of two LA techniques; BI with $4 \%$ Articaine and IDNB with $2 \%$ lidocaine for the treatment of mandibular carious primary molars in children under ten years of age.

Method: A prospective study design was used to explore patient and carer's acceptance of the two local anaesthetic techniques. 96 patients aged 5-9 years and their carer's completed two questionnaires on treatment acceptance.

Result: A total of 49 (50\%) participants received BI with 4\% Articaine and 49 (50\%) had IDNB with 2\% lidocaine. Two patients had IDNB but no dental treatment was performed as patients could not cope with dental treatment, thus these participants did not complete the questionnaires. The majority of the children $(84.7 \%)$ and their carers (91\%) were happy with their experience at the dentist including the administration of the LA (61.5\% for BI and 64\% for IDNB), delivery of the dental treatment $(87.8 \%$ for BI and $81.6 \%$ for IDNB) and dentist management including dental teamwork (over $90 \%)$.

Conclusion: Both local anaesthetic techniques; BI with 4\% articaine and IDNB with 2\% lignocaine were accepted among patients and carers. Dental team attitude can significantly impact the treatment outcome in children. Establishing a clear communication between the dentist, the child patient and his/her carer as
\end{abstract} well as implementing good behaviour management techniques contribute significantly to treatment acceptance among children and carers.

\section{Introduction}

Fear-related behaviours have long been recognized as the most difficult aspect of paediatric patient management and can be a barrier to good care. Local anaesthesia (LA) forms the backbone of pain control techniques in dentistry and has a major role in dentistry for children. ${ }^{1}$

Inferior Dental Nerve Block (IDNB) mainly with $2 \%$ lignocaine with 1:80,000 epinephrine has been the LA technique of choice and the most frequent injection technique used for treatment of carious mandibular primary molars in children. ${ }^{2}$ This technique results in anaesthetising all the primary molars, canines, half of the tongue and lower lip on the side injected allowing for treatment of multiple teeth of the same quadrant at one appointment. However, several disadvantages have been associated with the IDNB. The technique is highly dependent on the operator's experience and patient factors. Several clinical studies showed that IDNB does not always result in successful pulpal anaesthesia even when performed by the most experienced clinician. A failure rate ranging between $38 \%-77 \%$ has been reported. ${ }^{3-7}$ The accessory nerve supply, variable course of nerve, variation in foramen position, presence of infection or inflammation, and patient's fear as well as anxiety can all contribute to IDNB LA technique failure. ${ }^{8}$ In addition, the duration of anaesthesia makes the uncomfortable numb feeling last long after the end of dental treatment, often resulting in lip, tongue or cheek biting. Moreover, a successful mandibular block involves a degree of difficulty that makes the injection stressful for both the clinician and the patient. Other disadvantages include greater incidence of complications associated with the technique such as trismus, haematoma or paraesthesia as a result of damage from the needle to the inferior alveolar or lingual nerves. ${ }^{9}$
Submit your Article | www.ologypress.com/submit-article

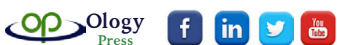

Citation: Tahmassebi JF, BaniHani A, Alzahrani F. Children and carer's experience and satisfaction of two local anaesthetic techniques; for treatment of carious mandibular primary molars in children. J Dent Maxillofacial Res. (20I8); I(I):3-II. DOI: I0.3088I/jdsomr.00004 
A more comfortable and pleasant alternative LA techniques to IDNB have been proposed to avoid the invasive and often painful nature of the IDNB. Buccal Infiltration (BI) with 4\% Articaine and 1:100,000 epinephrine is becoming increasingly widely used in paediatric dentistry especially for the treatment of carious mandibular molars in children above the age of 4 years. The infiltration is perceived as less stressful and easier for both child patient and dentist. ${ }^{10-11}$ In addition, Articaine has an intermediate-potency. It is a short-acting local anaesthetic with a metabolic shelf-life between 27 to 42 minutes, with a fast onset of action contributing to less unwanted soft-tissue anaesthesia for minimally invasive procedures. ${ }^{12}$

Few studies have evaluated effectiveness of mandibular BI with $4 \%$ Articaine and 1:100,000 epinephrine as a possible alternative to IDNB for the restoration of primary molars. No significant differences between infiltration and block were found except when pulpotomies were performed in the mandibular second primary molar, where it proved to be unreliable regardless of patient's age. ${ }^{13-16}$ In addition, IDNB was significantly more painful than BI anaesthesia, with some children aged 3 to 5 years old demonstrating negative behaviour following the IDNB injection. ${ }^{15}$ Limited data is available on children and parent's perception and satisfaction of both LA techniques; IDNB and BI. Therefore, the aim of this study was to explore children and carer's experience and satisfaction of their child's dental treatment under LA and compare their acceptance of two LA techniques; BI with $4 \%$ Articaine and IDNB with $2 \%$ lidocaine for the treatment of mandibular carious primary molars in children

\section{Materials and methods}

\section{Study population and ethical approval}

The study was conducted in specialist dental centre in the North of England, UK; Leeds Dental Institute (LDI)

Patients and carers who attended LDI between November 2013 and March 2015 for the treatment of their carious primary mandibular molar were approached to participate. Participants were included in the study if they met the following criteria:

1. Patient with no significant health problem (ASA Physical Status 1 and 2).

2. Aged 5-9 years and weighed more than $20 \mathrm{Kg}$ at time of dental treatment.

3. Had one carious primary mandibular molar that required either extraction or pulpotomy using LA.

4. Tooth had no history of infection (abscess) or swelling and no evidence of periapical pathosis, root resorption $>2 / 3$ of the root, or soft tissue infection/inflammation near site of injection.

5. Pre-operative radiographs were available.

6. English speaking patients and carers.

7. Carers and patients were able to give consent and assent.

The present study was part of a prospective randomised controlled trial aimed to assess and compare the anaesthetic efficacy of the BI using 4\% Articaine (1:100,000 epinephrine) with IDNB using 2\% lidocaine (1:80,000 epinephrine) in achieving adequate analgesia for extraction and pulpotomy of mandibular primary molars. All local anaesthetic injections and treatments were given by a single operator (F.Z) who was a paediatric postgraduate student under the supervision of consultants in Paediatric Dentistry. Each child received one treatment for one tooth only.

Approval was obtained from the Dental Research Ethics Committee (DREC), University of Leeds, the National Research Ethics Service (NRES), and the Medicines and Healthcare products Regulatory Agency (MHRA).

All carers gave written consent and children assent.

\section{Randomisation, allocation concealment and blinding}

Participants were randomly assigned into two groups; treatment group received BI with 4\% Articaine with 1:100,000 epinephrine, and control group received IDNB with $2 \%$ lidocaine with 1:80,000 epinephrine. Lignocaine topical anaesthetic (10\%) was applied for one minute to the dried injection site using cotton rolls prior to injection in both groups.

Simple randomisation procedure was applied. A random number generator algorithm was determined by computer. Each number $(0 / 1)$ determined the type of local anaesthetic to be used. A two legs randomisation $\log$ was created and used for the trial. Sequentially numbered, opaque, sealed envelopes were used. These envelopes were opened in sequence only after participant details and consent were obtained. Only patients were blinded to the type of injection.

\section{Sample size}

This equivalence trial was designed to assess the efficacy between two types of the local anaesthetic used with different injection techniques. The margin of equivalence, $\Delta$, was 0.20 and the range -0.20 to 0.20 was predefined as an acceptable range of completion rates between the two types of local anaesthetics. The equivalence margin was based on clinically important differences obtained from previous studies. The sample size of 98 children was calculated to be sufficient with $80 \%$ power to establish equivalence and significance level $5 \%$. Allowing for drop-off and failure to complete the trial, an estimated sample of 110 participants for the trial was required. A dropout rate of approximately $10 \%$ was assumed.

\section{Study measures}

Two new questionnaires were developed aimed to explore the child's and carer experience and satisfaction with LA, and compare both LA techniques; BI and IDNB in terms of participants acceptability and associated discomfort. Questionnaires were named 'Carers satisfaction with dental treatment ' and 'Children's satisfaction with dental treatment'. Both questionnaires were piloted prior to the start of the study among 10 of the molar children and their carers who attended LDI for routine dental treatment of their carious primary teeth. None of the questions were amended accordingly.

\section{Carers satisfaction with dental treatment questionnaire}

The questionnaire consisted of 5 closed and 7 open questions. Carers completed the questionnaire following their child dental treatment through face-to-face interview.

\section{Children`s satisfaction with dental treatment questionnaire}

The questionnaire consisted of 6 closed and 7 open questions using visual analogue scale. ${ }^{17}$ Patients completed the questionnaire following their dental treatment through face-to-face interview in the 
clinic. Open questions were discussed with the children thoroughly and responses were recorded and then transcribed. Children were encouraged to express their opinion about the dental injection and treatment they received at the dentist.

\section{Data analysis}

All data collected on carers and children acceptance of both LA techniques were presented in terms of proportions. All responses to the open questions were grouped into themes and analysed in terms of proportions. Chi-Square test was used to assess the significance of differences among the two LA groups in terms of the participants' responses to the questionnaires. Probability values of $\mathrm{P}<0.05$ were considered statistically significant.

\section{Results}

\section{Description of the sample}

In total 357 children attended the Paediatric Dentistry Department at LDI for routine dental treatment from which 98 children and their

Table I Description of the sample characteristics; age, gender, LA experience, tooth type and treatment received in total sample, control group (IDNB) and treatment group $(\mathrm{BI})$

\begin{tabular}{|c|c|c|c|c|}
\hline & Variable & IDNB & $\mathrm{BI}$ & Overall \\
\hline Age & Mean (SD) & $6.57(1.24)$ & $6.47(1.14)$ & $6.52(1.19)$ \\
\hline Gender & Male & $30(61.2 \%)$ & 23 (46.9\%) & $53(54.1 \%)$ \\
\hline LA experience & Yes & 31 (63.3\%) & 30 (6I.2\%) & $6 \mathrm{I}(62.2 \%)$ \\
\hline \multirow{2}{*}{ Tooth type } & First primary molar & 29 (59.2\%) & $23(46.9 \%)$ & $52(53.1 \%)$ \\
\hline & Second primary molar & $20(40.8 \%)$ & $26(53.1 \%)$ & $46(46.9 \%)$ \\
\hline \multirow{2}{*}{ Treatment } & Extraction & 37 (75.5\%) & 35 (71.4\%) & $72(73.5 \%)$ \\
\hline & Pulpotomy and SSC & $10(20.4 \%)$ & I 4 (28.6\%) & $24(24.5 \%)$ \\
\hline
\end{tabular}

Carer's satisfaction with their child's dental experience at the dentist

Most of the carers (90.8\%) in the current study believed that their child coped well with having the LA $(93.9 \%$ for the BI and $87.7 \%$ for the IDNB) (Table 2). In addition, the majority (95\%) agreed that LA facilitated having the dental treatment for their children $(98 \%$ for carers met the inclusion criteria of the study and completed the questionnaires; 49 received BI with $4 \%$ Articaine and 49 received IDNB with $2 \%$ lidocaine. Two patients had IDNB but no dental treatment was performed as patients could not cope with dental treatment. These patients did not complete the questionnaire on treatment acceptance. Responses to closed questions were analysed for 96 participants whereas responses to open questions were analysed for 75 participants due to limited information reported from the transcripts.

Table 1 describes the main characteristics of the sample. Children ranged in their age between 5 and 9 years with mean age of $6.5 \pm 1.19$. More than half of the sample were males (54.1\%). Regarding the participants` experience with LA and dental treatment, approximately two thirds $(62.2 \%)$ of the patients had LA at least once in their life mainly with lidocaine $(63.3 \%)$. In addition, the majority $(73.5 \%)$ had tooth extraction followed by pulpotomy and stainless steel crown (SSC) $(24.5 \%)$. No statistical significant difference was found between the LA groups in terms of patient's age, gender, previous LA experience, tooth treated and treatment received using Chi-Square.

Table 2 Carers responses to the closed questions of the `Parent`s satisfaction with dental treatment questionnaire $;$ Total sample $=98$ participants

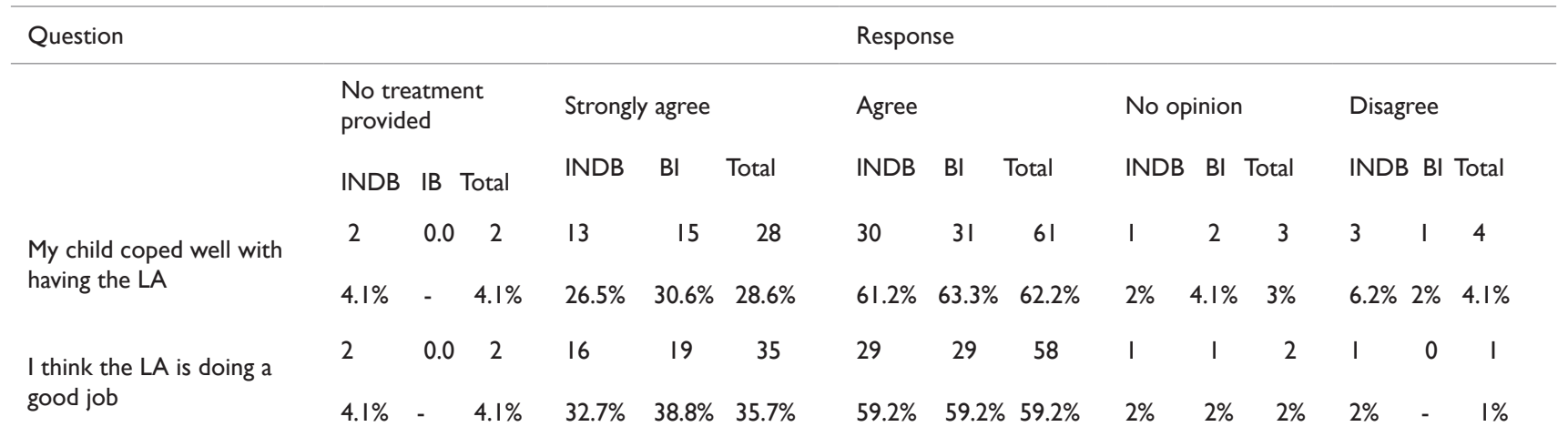


(Table 2 continue...)

\begin{tabular}{|c|c|c|c|c|c|c|c|c|c|c|c|c|c|c|c|}
\hline \multirow{2}{*}{$\begin{array}{l}\text { I have no concerns about } \\
\text { how LA works }\end{array}$} & 2 & 0.0 & 2 & 14 & 10 & 24 & 29 & 37 & 66 & 3 & 0 & 2 & I & 2 & 3 \\
\hline & $4.1 \%$ & - & $4.1 \%$ & $28.6 \%$ & $20.4 \%$ & $24.5 \%$ & $59.2 \%$ & $75.5 \%$ & $67.3 \%$ & $6.1 \%$ & - & $3.1 \%$ & $2 \%$ & $4 \%$ & $3 \%$ \\
\hline \multirow{2}{*}{$\begin{array}{l}\text { The dentist explained very } \\
\text { well why my child needed } \\
\text { the treatment }\end{array}$} & 2 & 0.0 & 2 & 18 & 21 & 39 & 28 & 28 & 56 & $\mathrm{I}$ & 0 & I & \multirow[b]{2}{*}{-} & & \\
\hline & $4.1 \%$ & - & $4.1 \%$ & $36.7 \%$ & $42.9 \%$ & $39.8 \%$ & $57.1 \%$ & $57.1 \%$ & $57.1 \%$ & $2 \%$ & - & $1 \%$ & & & \\
\hline $\begin{array}{l}\text { The dental team were } \\
\text { kind and helpful during my }\end{array}$ & 2 & 0.0 & 2 & 23 & 27 & 50 & 23 & 22 & 45 & I & 0 & I & & & \\
\hline child`s treatment & $4.1 \%$ & - & $4.1 \%$ & $46.9 \%$ & $55.1 \%$ & $51 \%$ & $46.9 \%$ & $44.9 \%$ & $45.9 \%$ & $2 \%$ & - & $1 \%$ & & & \\
\hline
\end{tabular}

Children satisfaction with their dental experience at the dentist

More than half of the children $(61.5 \% ; 59.2 \%$ for BI and $64 \%$ for IDNB) were happy about numbing their tooth and for having the tooth restored or extracted $(84.7 \% ; 87.8 \%$ for $\mathrm{BI}$ and $81.6 \%$ for the
IDNB) (Table 3). In addition, 96\% believed that the dental team was friendly (98\% and $94 \%$ for the BI and IDNB, respectively) and that the dentist explained the procedure of treatment well $(81.6 \%$ for BI and $85.7 \%$ for IDNB). No statistical significant difference was found in children`s responses between both LA groups; BI and IDNB using Chi-Square.

Table 3 Children`s responses to the closed questions of the `Children satisfaction with dental treatment questionnaire $;$ Total sample $=98$ participants

\begin{tabular}{|c|c|c|c|c|c|c|c|c|c|c|c|c|}
\hline \multirow[t]{3}{*}{ Question } & & & & & & & \multicolumn{6}{|c|}{ Response } \\
\hline & \multicolumn{3}{|c|}{ No treatment provided } & \multicolumn{3}{|c|}{ Positive } & \multicolumn{3}{|c|}{ Neutral } & \multicolumn{3}{|c|}{ Negative } \\
\hline & NDB & IB T & otal & INDB & $\mathrm{BI}$ & Total & INDB & $\mathrm{BI}$ & Total & INDB & $\mathrm{BI}$ & Total \\
\hline \multirow{2}{*}{$\begin{array}{l}\text { What do you think of } \\
\text { numbing your tooth }\end{array}$} & & & & 30 & 29 & 59 & 14 & 17 & 31 & 3 & 3 & 6 \\
\hline & & & & $64 \%$ & $59.2 \%$ & $61.5 \%$ & $30 \%$ & $34.7 \%$ & $32.3 \%$ & $6.4 \%$ & $6.1 \%$ & $6.3 \%$ \\
\hline \multirow{2}{*}{$\begin{array}{l}\text { Are you glad to have your } \\
\text { tooth fixed/taken out }\end{array}$} & 2 & 0.0 & 2 & 40 & 43 & 83 & 4 & 3 & 7 & 3 & 3 & 6 \\
\hline & $4.1 \%$ & - & $4.1 \%$ & $81.6 \%$ & $87.8 \%$ & $84.7 \%$ & $8.2 \%$ & $6.1 \%$ & $7.1 \%$ & $6.1 \%$ & $6.1 \%$ & $6.1 \%$ \\
\hline \multirow{2}{*}{$\begin{array}{l}\text { Was it ok to have your } \\
\text { tooth fixed/taken out }\end{array}$} & 2 & 0.0 & 2 & 34 & 37 & 71 & 8 & 7 & 15 & 5 & 4 & 9 \\
\hline & $4.1 \%$ & - & $4.1 \%$ & $69.4 \%$ & $75.5 \%$ & $72.4 \%$ & $16.3 \%$ & $14.3 \%$ & $15.3 \%$ & $10.2 \%$ & 8.2 & $9.2 \%$ \\
\hline \multirow{2}{*}{$\begin{array}{l}\text { The dentist explained } \\
\text { very well everything about } \\
\text { treating my tooth }\end{array}$} & 2 & 0.0 & 2 & 42 & 40 & 82 & 4 & 7 & II & I & 2 & 3 \\
\hline & $4.1 \%$ & - & $4.1 \%$ & $85.7 \%$ & $81.6 \%$ & $83.7 \%$ & $8.2 \%$ & $14.3 \%$ & $11.2 \%$ & $2 \%$ & 4.1 & $3.1 \%$ \\
\hline \multirow{2}{*}{$\begin{array}{l}\text { The dental team were kind } \\
\text { and friendly }\end{array}$} & 2 & 0.0 & 2 & 46 & 48 & 94 & I & I & 2 & & & \\
\hline & $4.1 \%$ & - & $4.1 \%$ & $93.9 \%$ & $98.0 \%$ & $95.9 \%$ & $2 \%$ & $2 \%$ & $2 \%$ & & & \\
\hline \multirow{2}{*}{$\begin{array}{l}\text { How did we look after } \\
\text { you when you had your } \\
\text { treatment }\end{array}$} & 2 & 0.0 & 2 & 37 & 42 & 79 & 8 & 5 & 13 & 2 & 2 & 4 \\
\hline & $4.1 \%$ & - & $4.1 \%$ & $75.5 \%$ & $85.7 \%$ & $80.6 \%$ & $16.3 \%$ & $10.2 \%$ & $13.3 \%$ & $4.1 \%$ & $4.1 \%$ & $4.1 \%$ \\
\hline
\end{tabular}

\section{Carers and children`s views toward the LA they received}

Three major themes appeared from carers and children responses to open questions. These themes were 'Experience of the anaesthetic procedures', 'Ease vs difficulty of dental treatment' and 'Perception of the dentist approach during the treatment'. Table 4 summarises the major themes and subthemes that emerged from the open questions.

\section{Theme one 'Experience of the anaesthetic procedures`}

Participants 'responses to open questions indicated that LA was a distinctive experience with a diverse outcome. Three subthemes emerged including 'Acceptability of having LA injection and how do children react to it', 'Carer's anxiety' and 'LA safety'. 
Table 4 Summary of the themes and subthemes that emerged from the open questions of the study questionnaires with examples on each subtheme

\begin{tabular}{ll}
\hline Theme & Examples \\
\hline
\end{tabular}

- Theme one `Experience of the anaesthetic procedures`

Subtheme 'Acceptability of having LA injection and how do children react to it

Subtheme 'Carer's anxiety'

Subtheme 'Local anaesthetic safety'

\section{- Theme two 'Ease vs difficult of dental treatment}

Subtheme ' fear or anxiety but will be happy to come back'

Subtheme 'Placing the crown/extraction as the hardest part but was happy with the outcome
"It went better than I thought" P43.

"Was good he was not complaining or crying... it was ok. Even though I was expecting him to cry" P70.

"Having the anaesthetic made it more comfortable than general” P3I.

"Fantastic, it worked fantastic to help my child" P7I.

"Having LA scares me...first time that he will experience having anaesthetic" P42.

"she was very brave and coped better than I thought she would..."P92.

"I don't have problem with the anaesthetic as long as there are no health implications and my child has pain free treatment"

"He was scared, not really painful he was happy at the end, happy to have the tooth out" P35.

"I think my daughter coped very well with the treatment, only thing is she might have been scared" P24.

A child commented (Eight years old, girl): “My treatment today was scary but I was a brave girl my tooth is out" C63.

"Hardest when the doctor was about to take the tooth out. She scares him about the "big push" P42.

"The actual extraction of the tooth was a little uncomfortable, but the rest was fine" P65.

"Having to keep his mouth open for a long time....getting restless... Yes, happy to get the treatment again" P48.

"Staying in a chair for 90 minutes....Yes, happy to come back"P73.

“Keeping his mouth open all the time..." P78.

Subtheme 'Difficult long process but happy with the results' 
(Table 4 continue...)

- Theme three`Perception of the dentist approach during the treatment

Subtheme 'Storybook, made it easy'

Subtheme 'Behaviour management procedures'

Subtheme 'Team work and dental staff

\author{
"Great idea to ease children into having dental treatment \\ done, she looked forward to coming to the dentist" PI3. \\ "I was very pleased with the way it was done especially the \\ story... clearly experienced with children" P47. \\ " the story was great, was well told and explained"P43.
}

\author{
"I am really happy with how my daughter has been treated \\ and very happy with the outcome ... thank you" PI4. \\ The child has commented (eight years old, boy): \\ "it was ok...I was scared ...but not any more"C39. \\ "I am very pleased; my daughter coped very well...the way \\ she had the treatment was fantastic." PI2.
}

"Staff and dental nurse were very understanding and kept my child very calm" P39.

"My daughter cooped very well with the anaesthetic, the staff were gentle and caring when giving the anaesthetic" P20.

Staff were great, especially as my daughter was quit scared" P 68.

\section{Subtheme `Acceptability of having LA injection and how do children react to it}

Participants reported wide range of views on how the LA was accepted among children in the present study. While some participants found the injection procedure an acceptable experience, others found it a difficult practice.

One mother described that the LA went better than what she expected: "It went better than I thought" P43.

A different mother had a similar opinion about LA:

"Was good he was not complaining or crying... it was ok. Even though I was expecting him to cry" P70.

Some other carers were happy with their child`s first experience with LA and described it as successful:

"It was the first time my son had this and I was concerned, however, he responded well to it...I liked the dental staff and their reassurance towards my son" P48.

In addition, a large proportion of carers reported that the LA was tolerable and helped in avoidance of pain during dental treatment:

"Having the anaesthetic made it more comfortable than general" P31.
"I think it was good thing to have helped him with the dental treatment" P40.

"Fantastic, it worked fantastic to help my child" P71.

"It helped my child to receive treatment with no pain, improves her attitude" P87.

Whereas some carers described having the LA injection as the hardest part of the treatment:

"My son did not like having the injection at all. He knew it because it was going to hurt. If there was no other way to numb the tooth without injection that would be marvellous" P 27.

"He does not like injections as he remembers them hurting when he was younger...he told me that he is not scared as before and he is happy to come next time for the last extraction!" P37.

"Its hard but what option do we have? After all he was well looked after and seemed okay" P61.

\section{Subtheme 'Carer's anxiety`}

Some carers were anxious about their child having the LA despite their child showed good behaviour and coped well during the LA injection: 
"Having LA scares me...first time that he will experience having anaesthetic" P42.

"she was very brave and coped better than I thought she would... "P92.

\section{Subtheme 'Local anaesthetic safety`}

Although many carers did not have concerns about the LA safety, one parent commented on this issue:

"I don't have problem with the anaesthetic as long as there are no health implications and my child has pain free treatment"

\section{Theme two 'Ease vs difficult of dental treatment'}

The second major theme was concerned with carers' responses and children's reaction to the dental treatment they received and its association with the final treatment outcome.

Three subthemes emerged including 'Fear or anxiety but will be happy to come back', 'Placing the crown/extraction as the hardest part but was happy with the outcome', and 'Difficult long process but happy with the results`.

\section{Subtheme 'fear or anxiety but will be happy to come back'}

More than half of the carers believed that their child found the treatment "scary". However, many of these carers commented on their child`s favourable behaviour during the treatment and being happy at the end of the treatment:

One mother stated that her son was scared but did not feel pain because of the anaesthesia:

"He was scared, not really painful he was happy at the end, happy to have the tooth out" P35.

"I think my daughter coped very well with the treatment, only thing is she might have been scared" P24.

A child commented (Eight years old, girl):

"My treatment today was scary but I was a brave girl my tooth is out" C63.

Another child mentioned (Six years old, girl):

"It was scary but I am fine now" C68.

\section{Subtheme 'Placing the crown/extraction as the hardest part but was happy with the outcome}

A quarter of the carers and children reported that the treatment itself was the most difficult part of their experience. Although children agreed that the treatment was difficult, many were happy to try it again and come for another treatment. More carers believed that tooth extraction was harder than placing a crown on:

"Hardest when the doctor was about to take the tooth out. She scares him about the "big push" P42.

"The actual extraction of the tooth was a little uncomfortable, but the rest was fine" P65.

None of the carers nor the children had commented on the tooth drilling or the pulpotomy procedure, the main complaint was about placing the crown on the tooth:

"Putting the silver cap on the tooth..." P51.
"Putting the crown in place and pressing down to it..." P97.

Subtheme 'Difficult long process but happy with the results'

Only nine carers believed that the long treatment time was the hardest part of their child's treatment experience, this was highlighted in the following carer`s responses:

"Having to keep his mouth open for a long time....getting restless... Yes, happy to get the treatment again" P48.

"Staying in a chair for 90 minutes.... Yes, happy to come back"P73.

"Keeping his mouth open all the time..." P78.

"Sitting down for long time was the hardest for my daughter"P79.

Theme three 'Perception of the dentist approach during the treatment

The third major theme was related to the management of the dental treatment and procedures including the dentist behaviour and attitude as well as the teamwork and how that might have affected the final treatment outcome.

Four subthemes emerged including 'Explaining the treatment procedures', 'Storybook, made it easy', 'Behaviour management procedures', and 'Team work and dental staff'.

\section{Subtheme 'Storybook, made it easy}

All participants in the present study were interested in the storybook developed by (F.Z). Carers left the following comments:

"Great idea to ease children into having dental treatment done, she looked forward to coming to the dentist" P13.

"I was very pleased with the way it was done especially the story... clearly experienced with children" P47.

" the story was great, was well told and explained"P43.

\section{Subtheme 'Behaviour management procedures'}

Majority of the carers had acknowledged the dental team and the dentist for being informative and friendly throughout the dental treatment:

"I am really happy with how my daughter has been treated and very happy with the outcome ... thank you" P14.

The child has commented (eight years old, boy):

“'it was ok...I was scared ...but not any more"C39.

"I though he is going to run away, that is why I asked my mum to come with me today for extra support, to be honest, I was not expecting him to sit on the chair and have dental treatment"P96.

"I am very pleased; my daughter coped very well...the way she had the treatment was fantastic." P12.

"She was initially needle phobia from past experience but from the staffs time and patience and the 'magic wand' the first time she was able to have a normal injection" P63.

\section{Subtheme 'Team work and dental staff}

The majority of the carers $(97 \%)$ reported that the dental team were kind and helpful during their child's treatment. 
Several of carers had clearly identified this in their comments:

"Staff and dental nurse were very understanding and kept my child very calm" P39.

"My daughter cooped very well with the anaesthetic, the staff were gentle and caring when giving the anaesthetic" P20.

Staff were great, especially as my daughter was quit scared" P 68.

"Staff and dental nurse were very understanding and kept my child very calm." P39.

\section{Discussion}

Dentists aim to provide dental treatment to children with as little pain or discomfort as possible. Pain control during dental treatment can be effectively achieved by LA. However, LA injection is often associated with anxiety and negative response especially when dealing with children. ${ }^{18}$ The current study has provided the opportunity to explore children and carer's experience and satisfaction of their child's dental treatment under LA and compare their acceptance of two LA techniques; BI with $4 \%$ Articaine and IDNB with $2 \%$ lidocaine for the treatment of mandibular carious primary molars in children.

As pain is subjective and can be associated with patient's fear and distress, the current study adopted a quantitative qualitative descriptive approach based on individual open-ended, semi-structured interviews. This study design aimed to provide a comprehensive representation of the data and has contributed to the main strength of the study. Two new questionnaires were developed for the aim of the study and were named 'Carers satisfaction with dental treatment ' and 'Children's satisfaction with dental treatment'. Among the other strengths of the study was that the researcher who carried out the LA and dental treatment to children had interviewed both patients and carers. This has facilitated the establishment of a good dentist-patient relationship allowing the researcher to interact and find out more about participants perception of LA and dental treatment they received.

This study`s principal findings were that the majority of the children $(84.7 \%)$ and their carers $(91 \%)$ were happy with their experience at the dentist specifically the delivery of the dental treatment $(72.4 \%$ for children) and dentist management including dental teamwork (94\% for children and $97 \%$ for parents). More than half of patients $(61.5 \%)$ in the present study were happy with the administration of the LA $(61.5 \%)$. Higher acceptance rate was reported in a study by BaniHani et al. ${ }^{19}$ where $76.4 \%$ of the 4 to 9 year olds were positive about numbing their tooth using BI technique. This could be due to several factors including clinician skills differences, different behaviour management techniques used in both studies and different patient anxiety levels. In addition, none of the patients in the latter study had tooth extraction, instead they all received complete caries removal followed by a filling or pulpotomy.

Participants 'responses were similar between the two LA groups; IB and IDNB indicating that both LA techniques were very much accepted for the treatment of mandibular molars in children. This could be explained by the fact that children were managed by a paediatric postgraduate student who was skilled at performing dental treatment including LA injection to children using appropriate behaviour management techniques and putting the child at ease.
This has helped the operator to build good relation and rapport with the child and his carer. In the present study the majority of the children and carers believed that the dentist explained very well why the child needed the dental treatment $(83.7 \%$ for children and $97 \%$ for carers) and have described the dental team as kind and helpful $(96 \%$ for children and $97 \%$ for carers). The latter have reflected again the importance of having a good and clear communication between the dentist, patient and carer. According to wright and Kupietzky. ${ }^{13}$ successful dental treatment provided to children is dependent on the proficiency of the dentist to guide them through their dental experiences. In addition, Pinkham ${ }^{20}$ indicated that behaviour management is equally important to the dexterity and knowledge the dentist have and both are considered as fundamental pillar in clinical success in children dentistry. This can be achieved through great understanding of the child`s feeling, and engaging with the child in discussion about what makes him feel anxious or worried as well as by listening to the child and showing him that he will be looked after. Implementations of good behaviour management strategies along with good clinical skills improve treatment outcomes in children.

In addition, the present study revealed different patterns of how carers would define successful LA and dental treatment, among these were whether the child looked comfortable in the dental chair, coped with the dental treatment, and willing to return to the dentist. The majority ( $91 \% ; 94 \%$ for BI and $87.7 \%$ for IDNB) of the carers believed that their child coped well with the LA and dental treatment he received at the dentist with some of them correlated coping with 'showing fearless" as well as 'not crying', and therefore, treatment was accepted by their child. Some other carers associated the child acceptance of dental treatment with the child showing good motivation for continuity of dental treatment in the future. This was highlighted as well by some children.

Several factors were found to contribute to the treatment acceptance among children and carers. These were dental fear and anxiety as well as dental team attitude. Children feelings and emotions mainly dental fear and anxiety can significantly impact their behaviour at the dentist. ${ }^{2122}$ Dental fear and anxiety-related behaviours are considered to be one of the most challenging aspects of paediatric dentistry. ${ }^{23}$ Only $20 \%$ of the patients in the present study were found anxious about having the LA and dental treatment from which $17 \%$ had the dental treatment done and the other 3\% struggled to accept the dental treatment. In addition, the majority of the children and carers reported the dental team being kind and friendly, and have endorsed them for explaining why the child needed the treatment suggesting that a good relationship between the dentist, children and their carers was established. The high acceptance rate $(84.7 \%)$ of the dental treatment among children in the study highlighted the importance of implementing good behaviour management techniques and establishing a good rapport with the child patient to reduce his dental anxiety and fear. The findings of this study were in agreement with a study by Zhou et al. ${ }^{24}$

However, the present study has some limitations. The study was conducted in a specialist care setting where dental treatment was performed by specialist paediatric dentistry and postgraduates under consultant supervision rather than by general dental practitioners to patients from a range of socio-economic backgrounds. The dental
Citation:Tahmassebi JF, BaniHaniA,Alzahrani F.Children and carer's experience and satisfaction of two local anaesthetic techniques; for treatment of carious mandibular primary molars in children.J Dent Maxillofacial Res. (20 I8); I (I):3-II. DOI: $10.3088 \mathrm{I} / \mathrm{jds}$ somr.00004 
staff were experienced at putting the child at ease and perform treatment using appropriate behaviour management techniques. In addition, participants who have had negative past experiences with LA and /or showed negative behaviour toward dental treatment had been excluded from the present study and were referred to have their dental treatment under general anaesthesia. Therefore, the final sample might not be a fully representative of the general population. Moreover, this was an explanatory investigatory study. There was no in-depth interview with carers and children. However, every effort was made to collect relevant data using different perspectives and using different techniques, which has offered new understanding that would not have emerged only using quantitative methods.

\section{Conclusion}

In conclusion, the majority of the children and carers were satisfied with their experience at the dentist. LA and dental treatment including pulpotomy and tooth extraction were well accepted among children and their carers. BI using 4\% Articaine (1:100,000 epinephrine) and IDNB using $2 \%$ lidocaine (1:80,000 epinephrine) were equally accepted for the treatment of carious mandibular primary molars in children.

Dental team attitude can significantly impact the treatment outcome in children. Establishing a clear communication between the dentist, the child patient and his carer as well as implementing good behaviour management techniques can contribute significantly to treatment acceptance among children and parents.

\section{Reference}

1. Peedikayil FC, Vijayan A. An update on local anesthesia for pediatric dental patients. Anesth Essays Res. 2013;7(1):4-9.

2. Moore PA, Hersh EV. Local Anesthetics: Pharmacology and Toxicity. Dent Clin North Am. 2010;54(4):587-599.

3. Chaney MA, Kerby R, Reader A, et al. An evaluation of lidocaine hydrocarbonate compared with lidocaine hydrochloride for inferior alveolar nerve block. Anesth Prog. 1991;38:212-216.

4. Cohen HP, Cha BY, Spångberg LS. Endodontic anesthesia in mandibular molars: A clinical study. J Endod. 1993;19(7):370-373.

5. Childers M, Reader A, Nist R, et al. Anesthetic efficacy of the periodontal ligament injection after an inferior alveolar nerve block. $J$ Endod. 1996;22:317-320.

6. Claffey E, Reader A, Nusstein J, et al. Anaesthetic efficacy of articaine for inferior alveolar nerve blocks in patients with irreversible pulpitis. $J$ Endod. 2004;30(8):568-571.

7. Mikesell P, Nusstein J, Reader A, et al. A comparison of articaine and lidocaine for inferior alveolar nerve blocks. J Endod. 2005;31(4):265-270.
8. Meechan JG. How to overcome failed anesthesia. British Dental Journal. 1999;186(1):15-20.

9. Harn SD, Durham TM. Incidence of lingual nerve trauma and postinjection complications in conventional mandibular block anesthesia. $J$ Am Dent Assoc. 1990;121(4):519-523.

10. Dudkiewicz A, Schwartz S, Laliberté R. Effectiveness of mandibular infiltration anaesthesia in children using the local anaesthetic Ultracaine (articaine hydrochloride). J Can Dent Assoc. 1987;53(1):29-31.

11. Corbett I, Kanaa MD, Whitworth J, et al. Articaine Infiltration for Anesthesia of Mandibular First Molars. J Endod. 2008;34(5):514-518.

12. Oertel R, Rahn R, Kirch W. Clinical pharmacokinetics of articaine. Clin Pharmacokinet. 1997;33(6):417-425.

13. Wright GZ, Kupietzky. Starkey PE, Gardener DE. Behavior Management in Dentistry for Children. John Wiley and Sons, INC; 2014 Manageing children's behaviour in the dental office. St Louis. CV Mosby Co. 1983.

14. Oulis CJ, Vadiakas GP, Vasilopoulou A. The effectiveness of mandibular infiltration compared to mandibular block anesthesia in treating primary molars in children. Pediatr Dent. 1996;18(4):301-305.

15. Sharaf A. Evaluation of mandibular infiltration versus block anaesthesia in paediatric dentistry. ASDC J Dent Child. 1997;64(4):276-281.

16. Al-Jumaili KA, Al-Rawi BA, Yaseen, GH. Evaluation of Mandibular Infiltration Compared to Mandibular Block Anaesthesia in Paediatric Dentistry. Al-Rafidain Dental Journal. 2009;9(1):32-37.

17. Carlsson AM. Assessment of chronic pain. I. Aspects of the reliability and validity of the visual analogue scale. Pain. 1983;16(1):87-101

18. Nakai Y, Hirakawa T, Milgrom P, et al. The children's fear survey schedule- dental subscale in Japan. Community Dent Oral Epidemiol. 2005;33(3):196-204.

19. BaniHani A, Deery C, Toumba KJ, et al. Effectiveness, Costs and Patient Acceptance of the Conventional and Biological Treatment Approaches for Carious Primary Teeth in Children. Caries Research. 2018.

20. Pinkham JR. Behavioral themes in dentistry for children. ASDC J Dent Child. 1990;57(1):38-45.

21. Locker D, Poulton R, Thomson W. Psychological disorders and dental anxiety in a young adult population. Community Dent Oral Epidemiol. 2001;29(6):456-463.

22. Porritt J, Marshman Z, Rodd H. Understanding children's dental anxiety and psychological approaches to its reduction. Int J Paediatr Dent. 2012;22(6):397-405.

23. Majstorovic M, Veerkamp JSJ. Relationship between needle phobia and dental anxiety. J Dent Child (Chic). 2004;71(3):201-205.

24. Zhou Y, Elaine C, Forbes G, et al. Systematic review of the effect of dental staff behaviour on child dental patient anxiety and behaviour. Patient Educ Couns. 2011;85(1):4-13. 